\title{
“O RESPEITO FEZ CHECK IN!”: ENTENDENDO A DIMENSÃO ATITUDINAL E PROGRAMÁTICA NOS HOTÉIS SOB A VISÃO DOS GESTORES HOTELEIROS E DOS CONSUMIDORES COM DEFICIÊNCIA FÍSICA
}

\section{RESUMO}

${ }^{1}$ Jefferson O. da Silva Lacerda

2 Rayane Fernandes Mano

${ }^{3}$ Nelsio Rodrigues de Abreu

${ }^{4}$ Renata Francisco Baldanza

As pessoas com deficiência historicamente eram relegadas às camadas mais inferiores da sociedade, tendo em vista sua condição, vista como limitante e erroneamente fora dos padrões. Ter uma deficiência, por muito tempo, foi sinônimo de estar doente, ser improdutivo e inválido. No decorrer dos anos, principalmente nas últimas décadas, esses indivíduos conquistaram direitos antes inimagináveis, como, por exemplo, o direito à acessibilidade em qualquer ambiente de consumo. Nesse sentido, este trabalho buscou identificar as ações de acessibilidade em meios hoteleiros, principalmente no tocante à dimensão atitudinal e programática, assim como verificou sua implantação na visão dos gestores hoteleiros e das pessoas com deficiência física consumidoras desse serviço. Para tanto, com uma abordagem qualitativa, foram feitas vinte e três entrevistas semiestruturadas cujos dados foram analisados por meio da análise do discurso. Observou-se que os gestores entrevistados sempre atrelam as dimensões de acesso tão somente às questões estruturais do hotel. Já os consumidores com deficiência, na maioria dos discursos, ligam a acessibilidade principalmente ao direito ir e vir. Diante disso, infere-se que esta pesquisa se mostra fundamental, tendo em vista que essas pessoas com deficiência física são consumidoras e têm o direito ao acesso em todos os ambientes, inclusive o serviço turístico.

Palavras-chave: Acessibilidade; Empresa Hoteleira; Hospitalidade; Marketing e Sociedade.

\section{"RESPECT IS CHECKED IN!": UNDERSTANDING THE ATITUDINAL AND PROGRAMMATIC DIMENSION IN HOTELS FROM THE VISION OF HOTEL MANAGERS AND CONSUMERS WITH DISABILITIES}

\begin{abstract}
Over the years people with disabilities were relegated to the lower strata of society. In many cultures, to have a disability was synonymous for being sick, being unproductive and invalid. These individuals conquered previously unimagined rights, for example, the right for accessibility in any consumer environment. So with a qualitative approach to descriptive research and through discourse analysis of twenty-three semi-structured interviews, this study identified what accessibility of shares hoteliers means, especially regarding the attitudinal and programmatic dimension. We also verified the implementation of the rights under the perspective of hoteliers and consumers with disabilities. Therefore, we observed that managers interviewed always point out the access dimensions as structural issues of the hotels. Consumers with disabilities, in most speeches, bind accessibility primarily for the right to come and go. Therefore, the results showed that this research is relevant, given that people with physical disabilities are consumers and have the right of access in all environments, including tourism services.
\end{abstract}

Keywords: Accessibility; Hotel Company; Marketing and Society.

\footnotetext{
${ }^{1}$ Doutorando em Administração pela Universidade Federal de Minas Gerais - UFMG, Belo Horizonte, Minas Gerais, (Brasil). Membro do Grupo de Pesquisa GPCiber (Consumo e Cibercultura). E-mail: jeffersoncantalice3@gmail.com

${ }^{2}$ Mestre em Administração pela Universidade federal da Paraíba - UFPB, João Pessoa, Paraíba, (Brasil). Professora pela Universidade Estadual da Paraíba - UEPB. E-mail: rayfernandes87@ gmail.com

${ }^{\mathbf{3}}$ Doutor em Administração pela Universidade Federal de Lavras - UFLA, Lavras, Minas Gerais, (Brasil). Professor Associado da Universidade Federal de Paraíba - UFPB, João Pessoa, Paraíba, Brasil. E-mail: nelsio@ gmail.com

${ }^{4}$ Doutora em Comunicação pela Universidade Federal da Bahia - UFBA, (Brasil). Docente no Curso de Administração na Universidade Federal da Paraíba - UFPB, João Pessoa, Paraíba, Brasil. E-mail: renatabaldanza@ gmail.com
} 


\section{INTRODUÇÃO}

Os estudos inseridos na esfera do macromarketing - abordagem interdisciplinar que tem como foco o desenvolvimento social (Peterson, 2006) têm como foco o marketing social ${ }^{5}$, a qualidade de vida, a ética e educação do consumidor, o marketing de lugares ligado ao apego do local, o bem-estar do consumidor, o consumo sustentável, a vulnerabilidade do consumidor, dentre outros. Inseridas nos estudos do marketing e sociedade encontram-se pesquisas como as de Shi, Cole e Chancellor (2012) e Silva, Abreu e Gosling (2015), que visam entender várias classes de consumidores, a saber: crianças, adolescentes, idosos, noivas, grávidas, estrangeiros e grupos minoritários (inclusive as pessoas com deficiência).

Esses grupos minoritários estão inseridos em uma sociedade multicultural, a qual reconhece as diferenças linguísticas, raciais e culturais, bem como as várias minorias, mas muitas vezes não adota políticas para integrar essas minorias. Esse termo "minorias" é uma expressão muito utilizada para definir os grupos que são considerados em menor quantidade em certa sociedade. Esses grupos muitas vezes são marginalizados da sociedade a ponto de serem considerados problemas sociais, daí surge o preconceito, racismo, bem como outras fobias relacionadas às barreiras multiculturais.

Quando se fala em minorias, entende-se que tais grupos formam parte de uma pequena porcentagem da sociedade, mas na realidade o que se observa não é isso. Ao se tomar os grupos intitulados "minoritários" como grupos sociais, se observará que a sociedade é, na verdade, composta por vários desses grupos, ou seja, várias porcentagens de grupos "minoritários" que resultam na totalidade social. Dessa forma, claramente se observa que a sociedade é composta pelos seguintes grupos: "o negro", "o branco", "o índio", "o homem”, "a mulher", "a criança", "o idoso", "a pessoa com deficiência", dentre outros.

No tocante às pessoas com deficiência, inseridas nesse bloco, pelo fato de possuírem alguma deficiência, estas podem ser sujeitas a certas barreiras de acesso, como, por exemplo, a barreira atitudinal e programática. A dimensão atitudinal concerne à educação da sociedade como um todo e, sobretudo, dos profissionais com poder de decisão. Já a dimensão programática diz respeito à eliminação das barreiras invisíveis existentes nos decretos, leis, regulamentos, normas, políticas públicas (Sassaki, 2009).

Diante das referidas dimensões, muitas vezes os indivíduos com deficiência física são impelidos a pagar por serviços extras e isso consequentemente eleva os custos da hospedagem. Eles, por serem considerados sujeitos "especiais" e que necessitam de "cuidados" especiais, são e estão sujeitos a pagar mais para ter (o que lhes é de direito) um serviço melhor. Frente a isso, observa-se que o correto (leia-se o que é ex proprio jure ${ }^{6}$ ) não é a pessoa com deficiência precisar se adaptar à sociedade, mas é a sociedade que deveria se adaptar e oferecer serviços e produtos a todos, respeitando a diversidade, bem como as diferenças.

De acordo com o censo populacional feito em 2010 pelo Instituto Brasileiro de Geografia e Estatística (IBGE), cerca de $24 \%$ da população brasileira possui algum tipo de deficiência, e essa porcentagem corresponde a mais de 45 milhões de pessoas. O maior número de pessoas com deficiência se encontra no Nordeste, no qual $21,2 \%$ delas declaram ter deficiência visual, $7,8 \%$ deficiência física, 5,8\% deficiência auditiva e 1,6\% deficiência mental ou intelectual. Além disso, o referido censo apontou que o Brasil segue muito atrasado no quesito acessibilidade, pois apenas $4,7 \%$ das vias urbanas contam com rampas para cadeirantes (IBGE, 2010).

Sabendo disso, o objetivo principal desta pesquisa foi identificar as ações de acessibilidade em meios de hospedagem (hotéis) principalmente no tocante à dimensão atitudinal e programática, assim como verificar sua implantação na visão dos gestores hoteleiros e das pessoas com deficiência física consumidoras desse serviço.

Para tanto, este artigo destaca, em sua estruturação, um levantamento teórico que enfatiza, primeiramente, aspectos que esclarecem alguns dos obstáculos que os consumidores com deficiência encontram em seu cotidiano, bem como leis que vêm trazendo direitos necessários como acessibilidade, prioridade entre outros. Em seguida, ainda no campo da literatura, apresenta uma breve relação entre os produtos e serviços turísticos e esse público especificamente. Como método, escolheu-se uma pesquisa de caráter exclusivamente qualitativo, do tipo descritiva. Como resultados, observou-se que, apesar dos esforços legais (Lei 8.078/1190, Lei 11.771/2008, entre outras), nem

\footnotetext{
${ }^{5}$ Marketing Social significa uma tecnologia de administração da mudança social associada ao projeto, à implantação e ao controle de programas voltados para o aumento da disposição de aceitação de uma ideia ou práticas sociais em um ou mais grupos adotantes escolhidos como alvo. Recorre a conceitos de segmentação de mercado, pesquisa de consumidores, desenvolvimento e testes de conceitos de produtos, comunicação direta, facilitação, incentivos e teoria da troca, para maximizar a resposta dos adotantes escolhidos como alvo. Kotler \& Roberto (1992, p. 25).

6 Termo em latim que significa "por direito próprio".
} 
toda estrutura turística engloba ações que, de fato, possibilitam ao consumidor turista que possui limitações físicas o conforto necessário para que sua experiência turística se dê de forma plena. Embora existam exceções, como se poderá constatar nos pormenores dos resultados.

\section{REFERENCIAL TEÓRICO}

\section{Consumidor com Deficiência}

Todos os indivíduos, com ou sem deficiência, estão diariamente sujeitos às necessidades e aos desejos os quais são supridos mediante o consumo. Essas necessidades vão desde alimentação, compra de roupas, consumo de programas culturais, bem como outros bens de consumo (Ruddell \& Shinew, 2006). No entanto, muitos são os obstáculos enfrentados diariamente pelas pessoas com deficiência, dificuldades essas que vão desde o âmbito profissional até o pessoal.

Ao se tomar a educação como o aspecto básico para a formação de qualquer pessoa, observa-se que poucos docentes estão preparados para educar alunos com alguma deficiência, além disso, a falta de equipamentos adequados dificulta ainda mais o acesso à educação para esses alunos (Manente, Rodrigues \& Palamin, 2007). Já no dia a dia, algumas das barreiras que dificultam às pessoas com deficiência desempenharem seu papel de consumidor são: as escadas, a falta de rampas, os obstáculos nas calçadas, a falta de sinalização adequada, transporte coletivo, dentre outros (Schivitz, 2007).

Baker, Holland e Kaufman-Scarborough (2007), ao estudarem os problemas que as pessoas com deficiência enfrentam em lojas de varejo e utilizando-se do método de incidente crítico, inferiram que o que os indivíduos com deficiência mais desejam quando entram em uma loja é serem vistos como consumidores. Segundo os autores, o que acontece é exatamente o contrário, pois os atendentes, na maioria das vezes, são incapazes de percebê-los como potenciais consumidores, estigmatizando-os apenas como deficientes. Para tanto, outro fator que atrapalha o consumidor deficiente é o despreparo dos atendentes, os quais possuem pouca ou nenhuma instrução de como tratá-los.

Nos Estados Unidos, desde 1990 existe uma lei que garante a acessibilidade das pessoas com deficiência a estabelecimentos comerciais, a Americans With

\footnotetext{
7 Disponível em:

http://www.ada.gov/pubs/adastatute08.htm Acesso em: 20 de abril de 2016.
}

Disabilities Act (ADA) ${ }^{7}$. E, embora muitas lojas do referido país já estejam adaptadas para as necessidades dessas pessoas, ainda existem outras que precisam se adaptar (Kaufman-Scarborough \& Baker, 2005). O que na realidade essa lei viabiliza a esses indivíduos é a possibilidade de serem vistos como consumidores, bem como possibilita a acessibilidade no âmbito arquitetônico, atitudinal e comunicacional.

No Brasil, por sua vez, o decreto-lei no $5296^{8}$, de 2 de dezembro de 2004, regulamenta as leis que dão prioridade de atendimento às pessoas com deficiência e estabelece normas gerais e critérios básicos para a promoção da acessibilidade, mas o país ainda está longe de oferecer condições ideais para que as pessoas com deficiência possam consumir (Schivitz, 2007). Esses consumidores representam um segmento de compra importante e cada vez mais poderoso (Goodrich \& Ramsey, 2011), por essa razão, o número de estudos desenvolvidos na última década destaca o potencial das pessoas com deficiência como segmento de mercado (Shi et al., 2012).

Para tanto, a promulgação de leis que (re)afirmem a acessibilidade em ambientes públicos e privados está inserida na teia de relações, cujo objetivo principal é dar condições de participação social, permitindo assim que os sujeitos com deficiência circulem pelos mais diversos ambientes e consumam. Dessa forma, para que ocorra o efetivo consumo, as pessoas com deficiência devem estar incluídas na sociedade, mesmo que, para tal, se delimitem diversos níveis possíveis de participação social (Lopes, 2009).

Levando em consideração que o consumo individual está intrinsecamente ligado à identidade coletiva dos consumidores, o ato de "consumir" passou a ser um dos indícios mais comuns dos processos de identificação, levando em consideração que o que se consome fornece a comprovação de quem se é, ou seja, trata-se na realidade do intitulado self estendido. Dessa maneira, diante do atual panorama social, os sujeitos confirmam ou até criam suas identidades através de seus gostos, ou de alguma marca visível que trazem consigo, como, por exemplo, alguma deficiência (Campbell, 2006).

Dessa maneira, o que se observa, na realidade, é que nesse processo de construção da identidade pelo consumo as pessoas com deficiência se deparam com barreiras. Essas dificuldades não estão somente nos estabelecimentos comerciais, mas principalmente nos espaços sociais (Goulart, 2007). Além disso, existem também os problemas de comunicação, como, por exemplo, no caso dos deficientes auditivos, pois sua deficiência não é facilmente percebida e dificilmente se

8 Disponível em:

http://www.planalto.gov.br/ccivil_03/_ato20042006/2004/decreto/d5296.htm Acesso em: 19 de abril de 2016 . 
encontra um indivíduo fluente em Língua Brasileira de Sinais (Libras).

No âmbito dos serviços, por sua vez, com o desenvolvimento de instrumentos legais que asseguram os direitos dos deficientes, houve uma crescente preocupação com a qualidade dos serviços prestados às pessoas com deficiência. Dessa forma, a partir da exposição das características dos serviços, trabalhar-seá o consumo de pessoas com deficiência na esfera do Turismo9.

\section{A Acessibilidade no Serviço Turístico}

No Brasil, somente em 1995 se iniciou a discussão acadêmica desse tema em turismo. De acordo com Brinckmann e Wildgen (2003), o modelo de inclusão é o processo pelo qual a sociedade se adapta para incluir as pessoas com deficiência em seus sistemas sociais para que possam assumir seus papéis na sociedade. Sassaki (2006, p.17) destaca alguns princípios desse modelo: “celebração das diferenças, direito de pertencer, valorização da diversidade humana, solidariedade humanitária, igual importância das minorias, cidadania com qualidade de vida".

Mendes e De Paula (2008, p. 27) acrescentam que a sociedade inclusiva só existe se a diversidade humana for compreendida de forma a garantir às pessoas com deficiência uma vida autônoma e independente, em "que elas próprias possam tomar decisões, assumindo o controle de sua vida e quebrando os estigmas presentes em nossa sociedade". No campo do turismo, essa inclusão significa que um determinado atrativo ou serviço deve se adaptar para atender bem a pessoa com deficiência e não esta se adequar às limitações do empreendimento.

Para tanto, os espaços turísticos adaptados às necessidades do indivíduo formam juntos espaços sem limitações, sem barreiras, sem exclusão. Dessa forma, "fica claro que o importante não é o direito em si, seja para o lazer, para o esporte ou para o turismo. O importante, na inclusão, é que esse direito seja usufruído pelas pessoas com deficiência sem serem separadas das outras pessoas" (Sassaki, 2006, p.106), ou seja, uma inclusão espacial. Segundo Duarte e Cohen (2006), a inclusão espacial entre as pessoas permite trocas, estimula o estabelecimento de teias de relações, valoriza as experiências dos lugares e evita o esfacelamento das individualidades.

No contexto brasileiro, muitas pessoas com deficiência simplesmente não conseguem ter acesso aos espaços turísticos, pois ainda há, na grande maioria dos

9 Lei 11.771/2008/Art. 2o Para os fins dessa lei, considera-se turismo as atividades realizadas por pessoas físicas durante viagens e estadas em lugares ambientes de lazer, recreação e turismo, muitas barreiras arquitetônicas, atitudinais, comunicacionais, metodológicas, instrumentais e programáticas (Sassaki, 2003a). Na realidade, embora Kamio e Sassi (2010, p. 127) afirmem que "o segmento de pessoas com alguma deficiência é um novo nicho que começa a ser desvelado por profissionais do turismo", o que se percebe no Brasil é que o turismo adaptado, ou seja, voltado para as pessoas com deficiência, ainda encontra-se muito aquém do que se pode considerar como acessível para esse grupo.

Na visão de Sassaki (2003a), a sociedade é a principal responsável em eliminar as barreiras supracitadas, para que a partir disso as pessoas com deficiência possam ter acesso aos lugares, serviços, informações e bens necessários ao seu desenvolvimento pessoal, social, educacional e profissional. Dessa maneira, o serviço turístico adaptado tem como objetivo principal tornar os locais acessíveis fisicamente, ou seja, livres das barreiras arquitetônicas, bem como incluir na sociedade os princípios de inclusão (Shimosakai, 2008).

Para tanto, Sassaki (2009) elenca seis barreiras que são consideradas desafiadoras para as pessoas com deficiência, a saber: barreiras arquitetônicas (sem barreiras físicas), atitudinais (sem preconceitos, estereótipos, estigmas e discriminações nos comportamentos da sociedade para pessoas que têm deficiência), comunicacionais (sem barreiras na comunicação entre pessoas), metodológicas (sem barreiras nos métodos e técnicas de lazer, trabalho, educação) instrumentais (sem barreiras nos instrumentos, ferramentas, utensílios) e programáticas (sem barreiras embutidas em políticas públicas, legislações, normas).

Quanto à dimensão arquitetônica, a acessibilidade está ligada à possibilidade de autonomia e o acesso fácil nos aeroportos, terminais rodoviários, espaços urbanos, hotéis, museus, teatros, transportes coletivos, parques ecológicos, parques temáticos, locais de eventos, dentre outros. Para Burnett (1996), Upchurch e Seo (1996), Castell (2008) e Sassaki (2009), o problema com a acessibilidade nas instalações físicas é o mais comum para as pessoas com deficiência, além disso, o descaso com a dimensão arquitetônica inviabiliza que as pessoas com deficiência exerçam plenamente o papel de consumidor (Sassaki, 2009).

Corroborando a dimensão supramencionada, tem-se a dimensão comunicacional, a qual está ligada à adequação das sinalizações de locais (em atenção a pessoas com deficiência visual ou com baixa visão) e contratação de intérpretes da língua de sinais junto aos trabalhadores em serviços e locais de lazer (Sassaki, 2009).

diferentes do seu entorno habitual, por um período inferior a 1 (um) ano, com finalidade de lazer, negócios ou outras. 
No tocante à dimensão metodológica, evitar as barreiras refere-se à substituição da maneira tradicional (que não leva em consideração as necessidades especiais de certas pessoas) a fim de que os gestores de serviços estabeleçam novas propostas e acordos com os seus usuários que têm deficiência. Para tal, a dimensão instrumental contribui com busca pela adequação nos aparelhos, equipamentos, ferramentas e outros dispositivos que fazem parte dos locais, sejam estes públicos ou privados. Tradicionalmente, as pessoas que trabalham com hospitalidade ignoram as limitações físicas, sensoriais e mentais de algumas das pessoas com deficiência (Sassaki, 2009).

No que se refere à dimensão programática, esta tem como finalidade a eliminação das barreiras invisíveis existentes nos decretos, leis, regulamentos, normas, políticas públicas, barreiras essas que se apresentam implicitamente, mas que na prática impedem ou dificultam às pessoas com deficiência a utilização dos serviços. E, por fim, a atitudinal contribui de maneira geral, tendo em vista que esta engloba a educação da sociedade como um todo e, especialmente, dos profissionais com poder de decisão, mas ainda preconceituosos a respeito de pessoas com deficiência, e que por isso deixam de abrir oportunidades de lazer para esse segmento populacional (Sassaki, 2009).

\section{PROCEDIMENTOS METODOLÓGICOS}

Para este estudo, optou-se, para a coleta dos dados da pesquisa, pela realização de entrevistas em profundidade com roteiro semiestruturado. É importante enfatizar que por serem entrevistas semiestruturadas o investigador, embora possua um roteiro preestabelecido, possui também bastante flexibilidade para (re)formular novas questões no decorrer da entrevista, de acordo com a necessidade (Mattos \& Lincoln, 2005).

$\mathrm{O}$ roteiro das entrevistas abrangeu questões sociodemográficas, profissionais e perguntas ligadas diretamente ao objetivo da pesquisa, viabilizando assim a caracterização dos sujeitos da pesquisa e algumas inferências relevantes ao estudo. Ainda sobre os entrevistados, estes residiam nos seguintes estados brasileiros: Ceará, Minas Gerais, Paraíba, Pernambuco, Rio Grande do Sul, Rio de Janeiro e São Paulo. A escolha dos entrevistados, bem como dos seus respectivos Estados, foi de maneira aleatória e por conveniência. Isto é, à medida que os sujeitos se interessavam em contribuir para a pesquisa, o

10 Segundo a classificação da SBClass. Disponível em: http://www.classificacao.turismo.gov.br/MTURclassificacao/mtur-site/ Acesso em: 20 de abril de 2016. pesquisador entrava em contato para a realização da entrevista.

Diante disso, para o primeiro contato com os indivíduos, o pesquisador uniu-se a um grupo virtual (em uma rede de relacionamentos virtual) que trata de assuntos ligados a pessoas com deficiência. Nessa comunidade foi feito um convite de auxílio referente à pesquisa. Quando surgiu o primeiro interessado (dia 12 de dezembro de 2013), estabeleceu-se um contato inicial e, em seguida, foi dada a opção ao sujeito de ser entrevistado por telefone ou pelo chat. Esse primeiro informante foi entrevisto por telefone e na data supramencionada.

Assim, após o informante concluir a entrevista, era solicitado que o mesmo indicasse mais um amigo que se encaixasse no perfil da pesquisa e que também pudesse ser entrevistado. Utilizando-se dessa técnica, foram entrevistadas 15 Pessoas com Deficiência, sendo 7 destas por telefone e 8 através de chamada de vídeo no chat. As entrevistas duraram em média 50 minutos.

A última entrevista realizada com os sujeitos com deficiência foi realizada no dia 11 de janeiro de 2014. Isto é, o período de entrevistas durou cerca de um mês. Dessa forma, para o fechamento do corpus da pesquisa utilizou-se como parâmetro a saturação das informações, e para alcançar o número de entrevistados supracitados utilizou-se o método snowball, que consiste em uma técnica de pesquisa qualitativa, pela qual o conjunto de informantes é indicado por um ou dois informantes iniciais (Sampieri, Collado \& Lucio, 2006). Assim, a escolha da primeira PcD entrevistada se deu através de uma solicitação em uma comunidade da rede social na internet voltada para as PcDs.

Quanto aos empreendimentos hoteleiros, foram entrevistados 8 (oito) gestores dos hotéis (sendo 7 Hotéis e 1 Flat/Apart-Hotel $)^{10}$ localizados na orla de João Pessoa-PB ou nas proximidades desta. A primeira entrevista com os gestores foi realizada no dia 21 e a última no dia 26 de dezembro de 2013. A escolha do primeiro gestor foi aleatória e obedeceu ao acesso, já os outros gestores entrevistados foram elencados mediante indicação do primeiro, seguindo assim a técnica de snowball. Todas as entrevistas realizadas, dos consumidores com deficiência e dos gestores, totalizaram em 138 páginas transcritas.

No total, foram entrevistadas 23 pessoas, sendo 15 pessoas com deficiência física e 8 gestores hoteleiros. O roteiro da entrevista para os gestores abrangeu 6 (seis) questões abertas, além de 4 (quatro) questões sociodemográficas e profissionais que viabilizaram a caracterização dos gestores e dos hotéis pesquisados. Todas as entrevistas foram feitas pessoalmente e gravadas com um dispositivo de gravação contido no 
celular do pesquisador. Antes de iniciar as perguntas, era solicitada do gestor entrevistado a autorização e em seguida o nome completo. Todas as entrevistas foram realizadas pelo pesquisador.

No tocante ao procedimento de análise dos dados, nesta pesquisa, optou-se pela técnica de análise do discurso, a qual se adéqua ao escopo da pesquisa, bem como permite o reconhecimento de temas, codificações e intenções presentes na fala, ou seja, a análise do discurso visa obter significados nas falas dos indivíduos (Mozzato \& Grzybovski, 2011).

Seguindo os procedimentos de categorização e tratamento dos resultados, a análise do discurso proporciona a apreensão de significados oriundos do material documental que pode ser coletado por meio de entrevistas estando em concordância com a técnica de coleta de dados aplicada neste estudo. Sendo assim, considerou-se que a análise do discurso proporciona uma riqueza de dados a serem interpretados, atendendo satisfatoriamente ao objetivo central da presente pesquisa (Cappelle, Melo \& Gonçalves, 2003).

\section{RESULTADOS E DISCUSSÕES}

\section{Descrição dos Gestores Entrevistados e dos Equipamentos Hoteleiros}

Como já exposto, esta pesquisa buscou identificar as ações de acessibilidade em meios hoteleiros, principalmente no tocante à dimensão atitudinal e programática, assim como verificar sua implantação na visão dos gestores hoteleiros e das pessoas com deficiência física consumidoras desse serviço. Para tanto, foram entrevistadas pessoas com deficiência física consumidoras de serviços hoteleiros, bem como os gestores de alguns empreendimentos hoteleiros da cidade de João Pessoa-PB. Dessa maneira, para uma maior validação das informações relatadas foram ouvidas ambas as partes do processo de troca, demandantes e ofertantes dos serviços de hospedagem.

Foram entrevistados 8 (oito) gestores de empreendimentos hoteleiros localizados na orla de João Pessoa-PB ou nas proximidades desta. A escolha do primeiro gestor foi aleatória (como já exposto neste estudo) e obedeceu ao acesso, já os outros gestores entrevistados foram elencados mediante indicação do primeiro, seguindo assim a técnica de snowball. O resultado dessas entrevistas pode ser observado na tabela abaixo.

TABELA 01 - Perfil dos Gestores

\begin{tabular}{|c|c|c|c|c|c|}
\hline Gestores & Idade & $\begin{array}{l}\text { Formação } \\
\text { Curso }\end{array}$ & $\begin{array}{l}\text { Tempo na } \\
\text { Hotelaria }\end{array}$ & $\begin{array}{l}\text { O hotel já } \\
\text { recepcionou uma } \\
\text { PCD }\end{array}$ & $\begin{array}{l}\text { O hotel já } \\
\text { recepcionou grupo } \\
\text { de PCDs }\end{array}$ \\
\hline Gestor 01 & 54 & $\begin{array}{l}\text { Superior Completo } \\
\text { Ciências Sociais }\end{array}$ & 30 anos & Sim & Sim \\
\hline Gestor 02 & 34 & Ensino Médio & 13 anos & Sim & Sim \\
\hline Gestor 03 & 40 & $\begin{array}{l}\text { Superior Completo } \\
\text { Administração e Hotelaria }\end{array}$ & 20 anos & Sim & Não \\
\hline Gestor 04 & 31 & Ensino Médio & 11 anos & Sim & Não \\
\hline Gestor 05 & 32 & $\begin{array}{l}\text { Superior Completo } \\
\text { Turismo }\end{array}$ & 11 anos & Sim & Não \\
\hline Gestor 06 & 34 & $\begin{array}{l}\text { Superior Completo } \\
\text { Turismo }\end{array}$ & 5 anos & Sim & Não \\
\hline Gestor 07 & 36 & $\begin{array}{l}\text { Superior Completo } \\
\text { Direito e Hotelaria }\end{array}$ & 15 anos & Sim & Não \\
\hline Gestor 08 & 35 & $\begin{array}{l}\text { Superior Completo } \\
\text { Turismo }\end{array}$ & 13 anos & $\mathrm{Sim}$ & Não \\
\hline
\end{tabular}

FONTE: Dados da Pesquisa (2013).

Como se pode verificar na tabela acima, todos os gestores possuem a idade superior a 30 anos. Essa característica dos entrevistados refletiu uma suposição advogada pelo senso comum que atribui aos indivíduos 
com maior idade uma maior maturidade na tomada de decisão gerencial. Por essa razão, no meio hoteleiro, a existência de indivíduos ocupando os cargos gerenciais com idade inferior a 30 anos ainda é difícil, pois na maioria dos casos esses indivíduos conquistam o nível gerencial após alguns anos trabalhando na área.

Com exceção de 2 (dois) gestores, todos os outros 6 (seis) possuem uma formação superior. Dentre esses que possuem um curso superior, 5 (cinco) deles são formados Turismo ou Hotelaria. Tal dado expressa a importância dessas áreas para a formação dos gestores hoteleiros. Vale salientar que outro ponto que está atrelado à formação é a experiência na área turístico-hoteleira. Na pesquisa esse tempo de atuação no setor hoteleiro mostrou-se bastante variado, indo desde um gestor com 5 anos de experiência na área até outro com 30 anos.

No tocante à recepção de pessoas com deficiência, todos os gestores confirmaram que os seus respectivos hotéis já recepcionam algum hóspede com deficiência física. No entanto, grupo de pessoas com deficiência apenas 2 (dois) deles (hotéis 01 e 02) já hospedaram. No tocante à descrição dos hotéis, observou-se uma variação de 40 anos no tempo de fundação destes, ou seja, o mais recente possui apenas 2 anos de inauguração enquanto o mais antigo tem 42 anos. Essa disparidade no tempo do estabelecimento hoteleiro pode influenciar na visão e implantação (ou não) da acessibilidade, tendo em vista que, no Brasil, apenas depois do decreto-lei no 5296, de 2 de dezembro de 2004, foram estabelecidas normas gerais para a promoção da acessibilidade, ou seja, quando alguns hotéis foram construídos as leis voltadas às pessoas com deficiência, bem como à acessibilidade, ainda não estavam em tanta evidência.

Ainda sobre os hotéis, observou-se que todos os estabelecimentos possuíam mais de 50 Unidades Habitacionais (UHs), sendo esse o número mínimo para entrar na pesquisa. Dentre as empresas elencadas, a que apresentou maior número de UHs foi o Hotel 07 com 173 apartamentos e a que apresentou o menor índice foi o Hotel 08. Relacionando o número de
UHs com a quantidade de quartos apropriados para as pessoas com deficiência, obtém-se a porcentagem de acomodações adaptadas.

De acordo com a norma da ABNT NBR 9050 de 2004, em cada estabelecimento hoteleiro deve haver pelo menos $5 \%$ do total de unidades habitacionais acessíveis, ainda é recomendado que outros $10 \%$ do total de dormitórios sejam adaptáveis para a acessibilidade. No entanto, o que se encontrou com esta pesquisa não confirmou o que estabelece a ABNT NBR 9050, pois apenas 3 dos 8 hotéis apresentaram a porcentagem mínima de UHs acessíveis.

Ainda sobre a porcentagem, vale destacar que o hotel mais recente apresentou a maior porcentagem de UHs adaptadas (8\%), enquanto o mais antigo possui um dos menores índices $(1,1 \%)$. A empresa que apresentou o menor índice foi o Hotel 06, com a porcentagem inferior a $1 \%$. Na tentativa de justificar esse fato o gestor afirmou:

É muito restrito e como o perfil do hotel é um perfil bem de hotel de negócios, não tem um perfil de hotel de lazer, então isso restringe um pouco a presença de algum hóspee ou passageiro com necessidades especiais (Gestor 06).

A norma da ABNT NBR 9050 é bem clara quando determina a porcentagem de UHs em estabelecimentos hoteleiros, ou seja, independentemente do tipo ou classificação dos hotéis, estes devem seguir o mínimo que estabelece a norma. Além disso, observou-se nesta pesquisa que há, ainda que minimamente, pessoas com deficiência que viajam por motivos de negócios. Por essa razão, a afirmativa de que por ser um hotel de negócios não há a necessidade de quartos adaptados torna-se falsa diante dos dados apresentados. Além disso, o próprio Gestor 06 confirmou que recepcionou em 12 meses de 01 até 05 vezes uma pessoa com deficiência. Logo, é inegável a necessidade de mais quartos acessíveis nesse estabelecimento de hospedagem. Esses dados podem ser observados na tabela a seguir.

TABELA 02 - Descrição dos Hotéis

\begin{tabular}{|l|l|l|l|l|l|}
\hline Hotéis & $\begin{array}{l}\text { Tempo do } \\
\text { Hotel }\end{array}$ & $\begin{array}{l}\text { № de Unidades } \\
\text { Habitacionais } \\
\text { (UH) }\end{array}$ & $\begin{array}{l}\text { № de UH } \\
\text { Adaptadas }\end{array}$ & $\begin{array}{l}\text { \% de UH } \\
\text { Adaptadas }\end{array}$ & $\begin{array}{l}\text { Média de Hospedagem de } \\
\text { PCD em } \mathbf{1} \text { ano }\end{array}$ \\
\hline Hotel 01 & 17 anos & 111 & 5 & $4,5 \%$ & De 15 até 20 vezes \\
\hline Hotel 02 & 13 anos & 60 & 3 & $5 \%$ & De 15 até 20 vezes \\
\hline Hotel 03 & 10 anos & 84 & 4 & $4,7 \%$ & De 06 até 09 vezes \\
\hline Hotel 04 & 16 anos & 54 & 3 & $5,5 \%$ & De 01 até 05 vezes \\
\hline
\end{tabular}




\begin{tabular}{|l|l|l|l|l|l|}
\hline Hotel 05 & 3 anos & 51 & 2 & $3,9 \%$ & De 06 até 09 vezes \\
\hline Hotel 06 & 5 anos & 140 & 1 & $0,7 \%$ & De 01 até 05 vezes \\
\hline Hotel 07 & 42 anos & 173 & 2 & $1,1 \%$ & Mais de 20 vezes \\
\hline Hotel 08 & 2 anos & 50 & 4 & $8 \%$ & De 10 até 15 vezes \\
\hline
\end{tabular}

FONTE: Dados da Pesquisa, 2013.

Ainda sobre a descrição dos hotéis, observa-se que todos os estabelecimentos possuem uma considerável média de

Como já observado, Sassaki (2009) elenca seis barreiras que são consideradas desafiadoras para as pessoas com deficiência, porém, para atender aos objetivos deste trabalho, nessa dimensão de análise serão observadas apenas as seguintes dimensões: barreiras atitudinais e programáticas.

\section{Dimensão Atitudinal}

A barreira atitudinal está vinculada aos preconceitos, estereótipos, estigmas e discriminações presentes na sociedade. De acordo com alguns entrevistados, os direitos nem sempre são tão assegurados e as barreiras atitudinais, mesmo que de maneira sutil, ainda estão presentes na sociedade brasileira, como relata a PcD02 e a PcD07.

Primeiro eu conduzo a coisa como um usuário normal que busca uma diária [...]. Uma vez como turista indiquei as datas que eu queria na reserva e ela deu ok, aí quando eu disse que era deficiente, ela disse que não tinha vaga para deficiente (PcD02).

Certa vez eu liguei para um hotel para fazer uma reserva, daí quem atendeu simplesmente falou que o hotel na tinha nenhum tipo de adaptação pelo fato do hotel não receber esse tipo de gente (PcD07).

Hospedagem. Essa média, mesmo que seja mínima, como no caso do Hotel 06, ou máxima, como o Hotel 07 , confirma que seja motivada pelos negócios ou por lazer, é inegável que as pessoas com deficiência estão realizando viagens e consumindo os serviços turísticos e hoteleiros.

\section{Barreiras de Acesso nos Equipamentos Hoteleiros}

A estratégia utilizada pelo entrevistado $02 \mathrm{e}$ relatada no excerto acima só ressaltou uma atitude costumeira nos estabelecimentos hoteleiros. Os hotéis, por não possuírem a quantidade suficiente de quartos adaptados ou talvez, nem os terem, rejeitam muitas solicitações de reservas feitas por pessoas com deficiência. Essa já se configura uma barreira atitudinal nos meios de hospedagem, pois o indivíduo com deficiência, assim como qualquer outro, tem o direito de consumir os serviços oferecidos por qualquer tipo de empresa turística.

No caso da atitude da encarregada de reservas que atendeu a PcD07, pareceu bem hostil, pois ela utilizou uma expressão que causou desconforto na entrevistada. Já no tocante à experiência relatada pela PcD02, foi tão desrespeitosa quanto a primeira, pois se desconhece a existência de vagas para deficientes e para não deficientes, vaga assim o é independentemente das particularidades dos hóspedes. Seguindo a lógica da encarregada de reservas, haveria também vagas para negros, idosos, gays, grávidas etc.? Vale salientar que essa atitude não pode ser considerada igual em todos os estabelecimentos, pois de acordo com um dos gestores entrevistados existem hotéis que não fazem distinções dessa natureza.

O que nós podemos oferecer, nós oferecemos, certo? Desde um atendimento diferenciado, das reservas, a atenção, também se preocupando em que a pessoa possa pedir, dando ao seu tipo de necessidade as acomodações no hotel (Gestor03).

Ainda sobre o atendimento do setor de reservas citado anteriormente, na melhor das hipóteses, talvez ela tenha entendido que a PcD02 estava solicitando um quarto adaptado. Mas um fato é inegável, a resposta dela causou um forte impacto negativo no entrevistado. Pelo que foi relatado, a atitude dela causou na PcD02 uma sensação de exclusão, segregação, discriminação devido a sua deficiência. Nesse caso específico, a barreira atitudinal foi referente à própria deficiência, mas existem casos em que essa barreira é sentida mediante a falta de preparo dos funcionários e a falta de qualidade nos serviços.

Essa segunda maneira foi exposta pela PcD03. Uma vez eu cheguei a um hotel e a pessoa da recepção não queria entrar com a minha cadeira de rodas. (PcD03). Foi percebido também através das entrevistas com as PCDs que, muitas vezes, a barreira atitudinal é 
tão perspicaz nos meios hoteleiros que chega a ser imperceptível para algumas pessoas com deficiência entrevistadas, ou seja, muitos entrevistados nunca sentiram qualquer indício de preconceito no transcorrer das suas hospedagens e confirmam isso usando tais discursos:

$\mathrm{Eu}$ acho que, como eu costumo ir a hotéis com acessibilidade, eles estão acostumados a receber pessoas cadeirantes, estão preparados (PcD11).

Tenho sempre momentos de solidariedade, em que os funcionários procuram facilitar ao máximo a minha estada. Mas, esclareço mais uma vez, minha mãe faz sempre ampla pesquisa sobre o hotel (PcD14).

Confirmando o que diz a literatura, a quebra da barreira atitudinal consiste na aquisição do conhecimento, ou seja, quando os indivíduos envolvidos com a hotelaria buscam entender alguns acontecimentos, tais como a acessibilidade, as pessoas com deficiência e como bem recebê-las. Segundo o Gestor01, os colaboradores do seu hotel possuem uma ótima preparação para atender as pessoas com deficiência e isso se deve ao fato de eles terem recebido um treinamento.

Primeiramente foi feita uma visita à FUNAD. Depois disso eu pedi para que eles viessem aqui pra dizer e mostrar como tratar, até porque o treinamento consiste em deixar o deficiente como sendo uma pessoal normal - e ele é normal! - a gente é que muitas vezes vê diferente. É por isso que $\mathrm{o}$ treinamento trazendo o pessoal da FUNAD foi interessante. Quando chega um cadeirante, tiram os impedimentos da mesa, já deixam bem adaptada a cadeira em volta dela. E isso já faz a diferença (Gestor01).

Uma situação que eu sempre acho agradável em relação a hotéis é eles (os hotéis) estarem ampliando e buscando novos recursos para a qualificação ao atendimento às pessoas com necessidades especiais (PcD09).

Comparando os diálogos das pessoas com deficiência entrevistadas e os dos gestores, fica mais uma vez claro que o preparo das pessoas envolvidas com a hotelaria contribui tanto para a hospitalidade quanto para a ruptura da barreira atitudinal. Essa barreira envolve vários fatores simples de serem resolvidos, pois, assim como o Gestor 01, outros estabelecimentos hoteleiros podem buscar auxilio nos órgãos competentes e fomentadores da causa ligada aos deficientes, tais como a Fundação de Apoio ao Deficiente (FUNAD) e Associação de Deficientes Motores (ADM).

Para tanto, conforme afirma Sassaki (2009), a dimensão atitudinal tem como berço a falta de instrução por parte dos profissionais hoteleiros, o que resulta em

\footnotetext{
11 Disponível em:

http://asdef.org.br/legislacao/ver/leis-do-municipio-de-
}

atitudes preconceituosas frente às pessoas com deficiência. Quando tal barreira é transposta, enxerga-se mais respeito a esses indivíduos. Além disso, observamse mais oportunidades de lazer para esse segmento populacional, o que os leva a se sentirem mais bem recebidos nos estabelecimentos hoteleiros. O que se observa é que, nos estabelecimentos hoteleiros, há um discurso "politicamente correto" quando se trata de pessoas com deficiência, isto é, uma educação no discurso, contudo, segundo a fala de alguns gestores, verifica-se não haver prioridade para a acessibilidade em tais empresas hoteleiras.

A título de orientação, o município de João Pessoa possui uma série de leis que visam inserir, proteger e amparar as pessoas com deficiência (Leis $11.894 / 2010$; 11.882/2010; 11.881/2010; 11.872/2010; $11.785 / 2009 ; 11.737 / 2009$, entre outras). Em 2007 foi criado o Estatuto Municipal da Pessoa com Deficiência (Lei 10.983/2007), que regulamentou uma série de lacunas legais que deixavam essas pessoas muitas vezes descobertas em seus direitos básicos. Essas leis estão disponíveis para consulta de forma sistematizada no site $^{11}$ da ASDEF (Associação de Deficientes e Familiares).

\section{Dimensão Programática}

A dimensão programática tem como principal função a eliminação das barreiras invisíveis existentes em decretos, leis, regulamentos, normas, políticas públicas, conceitos. Essas barreiras se apresentam muito sutilmente e na prática impedem ou dificultam que as pessoas com deficiência utilizem os serviços.

Para tanto, ao se comparar a visão sobre acessibilidade dos gestores e das pessoas com deficiência física, encontram-se conceitos distintos, mas complementares. Na realidade, essas diferenças se devem ao fato de serem várias opiniões, elaboradas sob duas óticas diferentes e em representações sociais distintas. Mediante a análise de todas as respostas sobre o que é acessibilidade, os discursos que melhor resumem a ótica de todas as pessoas com deficiência entrevistadas serão apresentados a seguir.

Acessibilidade é o que te leva a um caminho que você pode percorrer [...] um lugar, uma cidade, um estado, um país, um mundo, que você pode rodar, sem barreiras, por completo. Um lugar sem barreiras (PcD03).

Acessibilidade é o direito de eu estar onde eu quero, de estar de uma forma que eu me sinta segura, confortável, que eu consiga fazer o necessário, o que eu fui fazer em determinado lugar e fazer. Por exemplo, o direito ao lazer, o direito ao estudo, eu acho que ter condições (PcD08).

joao-pessoa-sobre-pcd. Acesso em: 20 de abril de 2016. 


\section{“O Respeito fez Check In": Entendendo a Dimensão Atitudinal e Programática nos Hotéis Sob a Visão dos Gestores Hoteleiros e dos Consumidores com Deficiência Física}

Acessibilidade é para todos. Eu não tenho que fazer simplesmente adaptações, eu tenho criar acesso (PcD15).

Para tanto, a acessibilidade serve não somente para as pessoas com deficiência, mas para todos, dando as condições e possibilidades de alcance para utilização, com segurança e autonomia, de edificações públicas, privadas e particulares, dos seus espaços, mobiliários e equipamentos urbanos, proporcionando a maior independência possível e dando ao cidadão com deficiência ou àquele com dificuldade de locomoção o direito de ir e vir a todos os lugares que necessitar, seja no trabalho, estudo ou lazer. Enfim, respeitar as pessoas com deficiência é, acima de tudo, proporcionar um ambiente livre de barreiras e, consequentemente, viabilizar o acesso. Vale salientar ainda que deficiência não é sinônimo de doença, como assim pensam algumas pessoas.

Existem algumas praias aqui na Paraíba que não têm acessibilidade nenhuma, não tem escada... É ruim até pra nós, que somos pessoas com saúde, imagina pra quem precisa da acessibilidade (Gestor 04).

Ainda sobre o conceito de acessibilidade, mediante a análise de todas as respostas dos gestores hoteleiros entrevistados, os discursos que melhor resumem a ótica destes serão apresentados a seguir.

Acessibilidade é justamente atender ao cliente que tem alguma deficiência, e que logicamente dar a mesma importância ou até mais, por que devido a essa deficiência tem que dar uma atenção mais especial ainda, né!? (Gestor 02).

Acessibilidade é um acesso prioritário aos deficientes, às gestantes, aos idosos. São os acessos que priorizem estas pessoas (Gestor 05).

Ao se contrastar a visão dos consumidores com a dos gestores, infere-se que a forma de estes entenderem a acessibilidade está um pouco aquém do que realmente esperam e conceituam as pessoas com deficiência. $\mathrm{Na}$ realidade, elas não esperam um atendimento diferenciado, com menor ou maior importância e atenção, porque isso é uma atitude esperada para todos os hóspedes. Elas querem autonomia, ter a liberdade de transitar de forma livre e sem nenhuma barreira. Os indivíduos com deficiência física esperam, prioritariamente, poder exercer o direito de consumir livremente de bens e serviços.

No que se refere à demanda por serviços hoteleiros das pessoas com deficiência, alguns gestores entrevistados expressaram que esse grupo ainda não é um nicho de mercado muito forte, contradizendo o que advoga a literatura.

A gente recebe muito pouco esse público e quando recebe a gente não tem um treinamento ou estrutura para recebê-lo. Até no nosso próprio curso não ensina nada de como tratar as pessoas com deficiência (Gestor 05).

A gente não tem algo direcionado, específico, fechado. Em relação ao atendimento específico pra esse público, como o nível de procura é bem baixo, então isso não se torna algo essencial dentro da questão do hotel, até porque a gente recebe pouquíssimas solicitações desse público (Gestor 06).

Como observado no excerto extraído do discurso do Gestor 05 e 06, as políticas de acessibilidade voltadas para as pessoas com deficiência não são levadas em consideração, logo não são implantadas nos equipamentos hoteleiros, por alguns gestores julgarem desnecessário, tendo em vista a demanda desse público. No entanto, o que esses administradores hoteleiros esquecem é que a acessibilidade não é um diferencial, ou uma opção, trata-se de uma norma, uma lei outorgada e que deve ser cumprida. $\mathrm{Na}$ visão das pessoas com deficiência que foram entrevistadas, esses gestores estão perdendo um grupo de consumidores importante e economicamente ativos.

Muitos brasileiros com deficiência preferem viajar para fora do Brasil em busca de melhores qualidades nestes serviços e produtos. Sem contar que estão perdendo outras grandes fatias de Pessoas com Deficiência e idosos estrangeiros que detêm renda para viajar e buscar esses serviços (PcD13).

Para tanto, observa-se que, para que esses gestores consigam atender com qualidade a esse público, primeiramente eles devem ampliar o leque de possíveis consumidores e evitar problemas com possíveis acidentes com hóspedes, ou seja, evitar as barreiras que foram citadas anteriormente e viabilizar a autonomia destes nas áreas habitacionais, recreativas e alimentícias.

Trata-se de um ato de cidadania, um dever dos gestores e empresários, o respeito às leis do país e reconhecimento sobre a diversidade humana. Sem contar que o público desse segmento detém uma bela fatia de renda que permite o acesso ao trabalho e por isso as viagens são comuns hoje em dia para profissionais com deficiência. Existe uma grande demanda de PcDs que buscam o lazer e viagens, portanto consumidores como os demais cidadãos e por isso merecem todo o respeito e reconhecimento de gestores de equipamentos de lazer e turismo (hotéis, resorts etc.) (PcD07).

Como exposto anteriormente, um dos motivos da falta de interesse ou das atitudes equivocadas com relação às pessoas com deficiência é a falta de conhecimento sobre esse universo. Por essa razão, uma maneira de esses gestores entenderem melhor esse universo da acessibilidade seria eles procurarem alguma associação de deficientes, com uma estrutura boa, próximo onde eles morassem, para sugerir um possível 
treinamento com os colaboradores, ajuda na (re)adaptação das unidades habitacionais, bem como assessoria para evitar as barreiras de acesso.

Dessa maneira, conforme afirma Sassaki (2009), quanto à dimensão programática, ainda há, de fato, elementos invisíveis e discrepantes quanto aos interesses dentro das leis, normas e conceitos voltados para as pessoas com deficiência. Isto é, o que os gestores enxergam como algo dispendioso (e talvez até dispensável) dentro das normas, os consumidores com deficiência encaram como fundamental e digno de ser respeitado. Além disso, quanto ao conceito de acessibilidade, demandantes e ofertantes divergem em muitos aspectos, dificultando, assim, que na prática haja um verdadeiro e eficaz acesso aos serviços hoteleiros.

\section{CONSIDERAÇÕES FINAIS}

O objetivo principal desta pesquisa, que era "identificar as ações de acessibilidade em meios hoteleiros, principalmente no tocante à dimensão atitudinal e programática, bem como sua implantação na visão dos gestores hoteleiros e das pessoas com deficiência física consumidoras desse serviço", foi plenamente alcançado. Para tal, a revisão da literatura bem como as entrevistas e análises destas se revelaram propulsores para se atingir o referido objetivo.

Ainda sobre o objetivo principal da pesquisa, para que o mesmo fosse completamente atendido foi necessário entrevistar dois tipos de sujeitos, um principal, as pessoas com deficiência, e outro secundário, os gestores hoteleiros, para que a partir disso fosse possível identificar as barreiras atitudinais e programáticas, assim como a implantação destas na visão de ambos os sujeitos.

De acordo com as entrevistas com os gestores a hospitalidade, não apareceu como um critério fundamental para a qualidade nos serviços hoteleiros. Para eles, devido à falta de demanda das pessoas com deficiência, as ações voltadas para esses indivíduos não são consideradas fundamentais para as políticas do hotel. Por essa razão, alguns estabelecimentos hoteleiros, representados pelos gestores entrevistados, limitam-se a cumprir apenas o básico para alcançar um ambiente acessível. E, em alguns casos relatados pelos consumidores com deficiência, nem o básico alguns hotéis oferecem.

Observou-se que o ponto mais destoante foi com relação à demanda por serviços hoteleiros, pois enquanto os gestores afirmam veementemente a inexistência ou a baixa procura das pessoas com deficiência por serviços hoteleiros, os consumidores com deficiência elencam motivos, justificam e demonstram que consomem, com frequência, os serviços turísticos.

Outro ponto discordante foi com relação ao conceito de acessibilidade, pois os gestores hoteleiros entrevistados sempre atrelam o acesso às questões estruturais do hotel e, além disso, olvidam-se das outras dimensões apresentadas neste estudo. Já os consumidores com deficiência, na maioria dos discursos, ligam a acessibilidade ao ato de ir e vir, de poder consumir com autonomia e segurança, de ter os seus direitos assegurados e poder ter acesso a todos os ambientes do hotel, inclusive o recreativo.

$\mathrm{O}$ que se infere diante de tudo isso é que as pessoas com deficiência, de maneira geral, querem ser enxergadas como indivíduos ativos, isto é, elas sentem a necessidade de serem respeitadas como cidadãs dotadas de todo direito. Além disso, essas questões ligadas à acessibilidade residem mais nos aspectos da cidadania e não como um simples posicionamento e/ou uma segmentação de mercado. A princípio, tende-se a ver tais sujeitos como mais uma "fatia de mercado", mais um grupo homogêneo em si, contudo, eles são tão heterogêneos quanto qualquer outro grupo social e devem ser tratados cada qual dentro de suas individualidades.

Em termos acadêmicos, este trabalho pôde contribuir para o universo de trabalhos científicos na área de administração. Além disso, tal estudo está inserido na linha de pesquisa de marketing e sociedade, cujo foco é a o equilíbrio das trocas e a defesa do consumidor potencialmente vulnerável.

Para tanto, este estudo propõe uma ampliação dos estudos na esfera do Marketing Social, entendendo que a acessibilidade é um possível assunto estudado pelo marketing. Além disso, sugere-se que pesquisadores da área de marketing atentem para o bem-estar do consumidor com deficiência física, tendo em vista que é um grupo crescente no Brasil, como apontam os dados do IBGE (citado inicialmente), mas que em ambientes de consumo está sendo relegado à condição de inválido e improdutivo.

Dessa maneira, diante do que foi apresentado no decorrer do trabalho, pode-se concluir que muitos indivíduos com deficiência são impossibilitados de ter o pleno acesso aos meios de hospedagem, pois existem nesses ambientes as barreiras atitudinais e programáticas citadas por Sassaki (2003a, 2006, 2009).

Para tanto, a principal limitação desta pesquisa foi com relação aos informantes que muitas vezes pareciam desconfiados das reais intenções da entrevista. Além disso, muitas vezes os entrevistados divagavam sobre assuntos que não tinham uma relação direta com a pesquisa, para isso era necessário que o pesquisador estivesse retomando a centralidade da pesquisa. Para os estudos futuros sobre a acessibilidade nos serviços turísticos, propõe-se a realização de análises comparativas entre culturas distintas, sejam entre países ou mesmo entre as regiões do Brasil. 


\section{REFERÊNCIAS}

Associação Brasileira de Normas Técnicas (ABNT). (2002). NBR 9050: acessibilidade a edificações, mobiliário, espaços e equipamentos urbanos. Rio de Janeiro.

Baker, S. M.; Holland, J.; KaufmanScarborough, C. (2007). How consumers with disabilities perceive "welcome" in retail services capes: a critical incident study. Journal of Service Marketing, v. 21 , n. 3 , p. $160-173$.

Brasil. Senado Federal. (2003). Estatuto da pessoa portadora de deficiência: a natureza respeita as diferenças. 3. ed. Brasília: Senado Federal. Disponível em: http://www2.senado.gov.br/bdsf/item/id/7 Acesso em: 12 jul. 2013.

Brasil. Ministério do Turismo. Secretaria Nacional de Políticas de Turismo. (2006). Turismo e Acessibilidade: manual de orientações. MTUR. Brasília: Ministério do Turismo. Disponível em: http://www.turismo.gov.br/turismo/o_ministerio/public $\underline{\text { acoes }}$

/cadernos_publicacoes/18_Manual_Acessibilidade.htm 1 Acesso em: 13 jul. 2013.

Brinckmann, W. E.; Wildgen, J. S. (2003). Desafíos para los estudiosos del turismo: la construcción de la "sociedad inclusiva" y del "turismo accesible". Cuadernos de Turismo, n. 11, p. 41-58.

Burnett, J. (1996). What services marketers need to know about the mobility-disabled consumer. The Journal of Services Marketing, v. 10, n. 3, p. 320.

Campbell, C. (2006). Eu compro, logo sei que existo: as bases metafísicas do consumo moderno. In: ; BARBOSA, L. Cultura, consumo e identidade. Rio de Janeiro: FGV.

CappellE, M. C. A.; Melo, M. C. O. L.; GONÇALVES, C. A. (2003). Análise de conteúdo e análise de discurso nas ciências sociais. Organizações Rurais e Agroindustriais - Revista Eletrônica de Administração da UFLA, v. 5, n. 1.

Castell, L. (2008). Building access for the intellectually disabled. Facilities, 26(3/4), 117-130.

Duarte, C. R. S.; Cohen, R. (2006). Proposta de metodologia de avaliação da acessibilidade aos espaços de ensino fundamental. In: Seminário Internacional Nutau: Inovações Tecnológicas sustentabilidade, 2006, são paulo. Anais... São paulo: fau/usp.

Goodrich, K.; Ramsey, R. (2011). Are consumers with disabilities receiving the services they need? Journal of Retailing and Consumer Services.

Goulart, R. (2007). As viagens e o turismo pelas lentes do deficiente físico praticante do esporte adaptado: um estudo de caso. 2007. Dissertação (Mestrado em Turismo) - Universidade de Caxias do Sul, Caxias do Sul.

Instituto Brasileiro de Geografia e Estatística (IBGE). Censo demográfico 2010. Disponível em: http://www.ibge.gov.br/home/ presidencia/noticias/noticia_impressao.php?id_noticia= $\underline{2170}$ Acesso em: 10 maio 2016.

Kamio, L.; Sassi, O. C. (2010). Inclusão social no Turismo. Revista Multidisciplinar da UNIESP Saber Econômico, São Paulo, n. 9, jun.

Kaufman-Scarborough, C.; Baker, S. (2005). Do people with disabilities believe the ADA has served their consumer interests. The Journal of Consumers Affairs, v. 39, n. 1, p. 1-26.

Kotler, P.; Roberto, E. L. (1992). Marketing social: estratégias para alterar o comportamento público. Rio de Janeiro: Campus.

Lopes, M. C. (2009). Políticas de inclusão e governamentalidade. Educação \& Realidade, Porto Alegre, v. 34, n. 2.

Manente, M.; Rodrigues, O.; Palamin, M. (2007). Deficientes auditivos e escolaridade: fatores diferenciais que possibilitam o acesso ao ensino superior. Revista Brasileira de Educação Especial, v. 13 , n. 1, p. $27-42$.

Mattos, P.; Lincoln, C. L.(2005). A entrevista não-estruturada como forma de conversação: razões e sugestões para sua análise. Rev. Adm. Pública, v. 39, n. 4, p. 823-847, jul./ago.

Mendes, B. C.; DE Paula, N. M. (2008). A hospitalidade, o turismo e a inclusão social para cadeirantes. Revista Turismo em Análise, v. 19, n. 2, p. 329-343.

Mozzato, A. R.; Grzybovski, D. (2011). Análise de conteúdo como técnica de análise de dados qualitativos no campo da administração: potencial e desafios. RAC, v. 15, n. 4, p. 731-747, jul./ago. 
Peterson, M. (2006). Focusing the future of macromarketing. Journal of Macromarketing, v. 26, n. 2, p. 245-249, dez.

República, Presidência. Lei 11.771/2008 Política Nacional de Turismo. Disponível em: http://www.planalto.gov.br/ccivil_03/_ato20072010/2008/lei/111771.htm. Acesso em: 10/05/2016.

RepúblicA, Presidência. Lei 8.078/1990 Proteção do Consumidor. Disponível em: http://www.planalto.gov.br/ccivil_03/Leis/L8078.htm. Acesso em: 12/05/2016.

Ruddell, J.; Shinew, K. (2006). The socialization process for women with physical disabilities: the impact of agents and agencies in the introduction to an elite sport. Journal of Leisure Research, v. 38, n. 3, p. 421-444.

Sampieri, R. H.; Collado, C. F.; Lucio, P. B. (2006). Metodologia de pesquisa. 3. ed. São Paulo: MacGraw-Hill.

Sassaki, R. K. (2003a). Inclusão no lazer e no turismo: em busca da qualidade de vida. São Paulo: Áurea.

Sassaki, R. K. (2003b). Como chamar as pessoas que têm deficiência. São Paulo: RNR.

Sassaki, R. K. (2006). Inclusão: construindo uma sociedade para todos. 7. ed. Rio de Janeiro: WVA.
Sassaki, R. K. (2009). Inclusão: acessibilidade no lazer, trabalho e educação. Revista Nacional de Reabilitação (Reação), ano XII, mar./abr.

Schivitz, T. (2007). Acessibilidade: um passo para a hospitalidade nos meios de hospedagens. 2007. Trabalho de conclusão (Curso em Hospitalidade) Pontifícia Universidade Católica do Rio Grande do Sul, Porto Alegre.

Shi, L.; Cole, S.; Chancellor, H. C. (2012). Understanding leisure travel motivations of travelers with acquired mobility impairments. Tourism Management.

deficientes.

Shimosakai, R. (2008). Turismo para http://turismoadaptado.zip.net/ Acesso em: 10 jul. 2013.

Silva, J. O.; Abreu, N. R.; GOSLING, M. (2015). “Ao alcance de quem?!”: Uma Reflexão Sobre a Decisão de Compra das Pessoas com Deficiência Física sob a Perspectiva da Acessibilidade. Revista Economia e Gestão, Belo Horizonte, v. 15, n. 40, jul./set.

Upchurch, R.; Seo, J. (1996). Civic responsibility and marketing positioning: complying with the Americans with Disabilities Act. Facilities, v. 14 , n. $5 / 6$, p. 